\title{
Facile synthesis of TiN nanocrystals/graphene hybrid to chemically suppress the shuttle effect for lithium-sulfur batteries
}

J. Tu, H Li, T. Lan, SZ. Zeng, J. Zou, Q. Zhang, X. Zeng

\section{Abstract}

Herein, we present a microwave reduction strategy for the synthesis of reduced-graphene-oxide (rGO) supported TiN nanoparticle hybrid (TiN/rGO) under $\mathrm{N}_{2}$ atmosphere. The method involves GO reduction, metal oxide reduction and nitridation reaction in one single step. Due to TiN high conductivity and good interfacial affinity between it and lithium polysulfides (LiPSs), the prepared TiN/rGO-Sulfur (TiN/rGO-S) cathodes demonstrate rapid charge transfer, lower polarization, faster surface redox reaction kinetic and enhanced stability cycling performance than rGO-Sulfur (rGO-S) and $\mathrm{TiO}_{2} / \mathrm{rGO}-\mathrm{Sulfur}\left(\mathrm{TiO}_{2} / \mathrm{rGO}-\mathrm{S}\right)$ cathodes. The initial capacity reaches $1197.6 \mathrm{~mA} \mathrm{~h} \mathrm{~g}^{-1}$ with a reversible capacity of $888.7 \mathrm{~mA} \mathrm{~h} \mathrm{~g}^{-1}$ being retained after 150 cycles at $0.1 \mathrm{C}$.

Keywords

Lithium-sulfur batteries, Shuttle effect, Titanium nitride, Microwave reduction, Chemisorption 1. Introduction

To date, the electrical energy storage appliances ranging from portable electronics, cleanenergy vehicles to the intermittent renewable energy involving solar and wind energy in the modern smart electrical grid have made enormous strides, however, the high demand for such technological advancements is ever present [[1], [2], [3]]. Thus, the development of advanced battery systems with high power density, high capacity, low cost and long cycle life is desirable [[4], [5], [6]]. However, the energy density of current rechargeable lithium-ion batteries (LIBs) using electrodes based on $\mathrm{Li}^{+}$insertion chemistry is approaching its formidable limitation, making it exceedingly difficult to satisfy this rapidly growing area [[7], [8], [9]]. 
Over the past few years, rechargeable lithium-sulfur batteries (LSBs) are regarded as the most commercial potential energy storage system for the next-generation, due to its large theoretical specific capacity $\left(1675 \mathrm{mAh} \mathrm{g}^{-1}\right)$ and extraordinary energy density $\left(2600 \mathrm{Wh} \mathrm{kg}^{-1}\right)$, which is much higher than the corresponding values of extant LIBs [10]. Additionally, elemental sulfur possesses additional superiorities as a cathode material owing to its readily availability, relatively low-price, and non-poisonous [11].

Nonetheless, the practicality of reliable LSBs is still impeded by two main technical challenges. Firstly, the poor conductivity of sulfur and its discharging products (e.g. $\mathrm{Li}_{2} \mathrm{~S}$ and $\mathrm{Li}_{2} \mathrm{~S}_{2}$ ) lead to low utilization of active material [12]. Secondly, the easy dissolution and transportation of lithium polysulfide intermediates ( $\mathrm{LiPSs}, \mathrm{Li}_{2} \mathrm{~S}_{\mathrm{x}}, \mathrm{x}$ goes between 2 and 8) produced at the charging/discharging processes trigger the so-called 'shuttle effect', which can result in rapid capacity degradation and low coulombic efficiency [13]. Therefore, the electronic conductivity ability and reduction of the 'shuttle effect' are issues that urgently need to be rectified for the development of $\mathrm{Li}-\mathrm{S}$ batteries [14].

Currently, extensive explorations have been conducted to tackle these obstacles of LSBs. One of the effective strategy is to make a sulfur composite with carbon-based materials because of its high-conductivity, great specific surface area, low cost and diverse morphologies, such as hollow carbon nanospheres $[15,16]$, carbon nanotubes [17,18], carbon nanobelts [19], activated carbon and graphene [20,21]. Among them, two-dimensional (2D) graphene nanosheets are considered to possess an exceptional matrix material for sulfur nanoparticles, owing to superb electronic conductivity, ultrathin thickness, structural flexibility, chemical stability and high surface-to-volume ratio. Numerous reports have examined the fabrication of graphene-sulfur hybrid as cathode materials for LSBs. However, these studies show that pure graphene as a sulfur host material is only advantageous to ameliorate the terrible electronic transmission capability of elemental sulfur but has little effect on restricting the migration of LiPSs because 
of the non-polarity of carbon atom [22]. Although the dissolution and shuttle effects of LiPSs have been restrained to some extent, the correlated capacity still suffers significant decay upon long-term cycling.

Recent reports have shown that the cycle stability of carbonaceous based electrode materials is greatly enhanced after modification with polar metallic oxide nanoparticles such as $\mathrm{SiO}_{2}$ $[23,24], \mathrm{SnO}_{2}[25,26], \mathrm{TiO}_{2}[27], \mathrm{Ti}_{4} \mathrm{O}_{7}[28,29]$ and $\mathrm{MnO}_{2}$ [30], which have been employed as effective polysulfide adsorbents owing to the strong chemical binding to LiPSs. Nevertheless, most aforementioned metal oxides are semiconductors or insulators, which seriously obstruct electron transmission and conversion of soluble LiPSs into insoluble products, promoting lower sulfur utilization and inferior rate performance. Therefore, it is imperative to introduce certain bi-functional materials that combine inherent metallic conductivity and strong adsorption capability to LiPSs into the sulfur electrode to remove these blockages.

Compared to metal oxide, transition-metal carbides or nitrides (TiC [31], WC [32], MoC [33], TiN [34], $\mathrm{WN}$ [35], VN [36], ZrN [37], $\mathrm{NbN}$ [37], etc.), possessing high conductivity, chemical stability, a polar surface and electrochemical catalytic activities, have recently become of interest. Goodenough's group were the first to present a novel matrix material of TiN with mesoporous morphology, which was used as the conductive agent and adsorbent for LiPSs and prepared by a solid-solid thermal process under $\mathrm{NH}_{3}$ atmosphere [38]. Fan et al. designed and fabricated a MoN supported graphene (MoN/G) inter-layer via an annealing process using $\mathrm{NH}_{3}$ as the reducing agent and nitrogen sources at $850{ }^{\circ} \mathrm{C}$ for $6 \mathrm{~h}$. The obtained MoN/G inter-layer displayed strong anchoring capacity for LiPSs as well as accelerated $\mathrm{Li}_{2} \mathrm{~S}$ decomposition ability [39]. Zhang et al. synthesized a $\mathrm{Ti}_{3} \mathrm{C}_{2} \mathrm{MXene}$ conductive paper for sulfur host materials, which show good mechanical stability, excellent conductivity and unique chemical adsorption of LiPSs. $\mathrm{Ti}_{3} \mathrm{C}_{2} \mathrm{MXene}$ was prepared by exfoliation of $\mathrm{Ti}_{3} \mathrm{AlC}_{2}$ powders in the $\mathrm{HCl}$ and $\mathrm{LiF}$ mixed solution ( $\mathrm{HCl} 6 \mathrm{M} 10 \mathrm{~mL}$, $\mathrm{LiF} 0.666 \mathrm{~g}$ ). Furthermore, the $\mathrm{Ti}_{3} \mathrm{AlC}_{2}$ powders were synthesized 
by mixing $\mathrm{TiC}$ and $\mathrm{Ti}_{2} \mathrm{AlC}$ particles through ball milling for $18 \mathrm{~h}$, and then heated at $1350{ }^{\circ} \mathrm{C}$

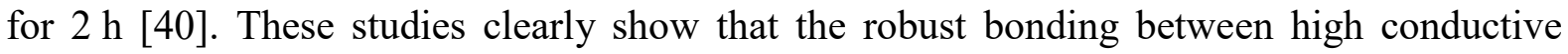
transition-metal nitrides or carbides and LiPSs can greatly mitigate the shuttle effect. Nevertheless, the preparation technique of metal carbides or nitrides usually requires rigorous synthesis conditions, such as high temperature, corrosive acid and toxic gases reactants, leading to excessive energy consumption, environment damage and low-efficiency, making unsuitable for large-scale industrial production.

Herein, we introduce a microwave-assisted reduction strategy for the preparation of layered reduced oxide graphene sheets supported TiN nano-particles composite (TiN/rGO) under $\mathrm{N}_{2}$ atmosphere. $\mathrm{TiO}_{2}$ nano-particles hybridized with graphene oxide $\left(\mathrm{TiO}_{2} / \mathrm{GO}\right)$ were first prepared by a facile solvent method using tetra- $n$-butyl titanate (TBOT) as the titanium source at room temperature. These composites were completely transformed into TiN/rGO within 10 min by microwave heating reduction. The as-prepared TiN/rGO hybrid served as the sulfur host material, exhibiting several advantages: the lamellar graphene structure affords channels that allow lithium ions and electrons to be freely transferred; the well-distributed TiN nanoparticles anchored on graphene sheets act as an adsorbent, trapping LiPSs owing to enhanced chemical interactions, which alleviates the shuttling effect; the metallic TiN forms an excellent interface with LiPSs improving reductive catalyization of sulfur and oxidation of $\mathrm{Li}_{2} \mathrm{~S}$.

\section{Experimental}

\subsection{Synthesis of anatase $\mathrm{TiO}_{2} / \mathrm{rGO}$}

The $\mathrm{TiO}_{2} / \mathrm{GO}$ hybrid was synthesized by a facile in situ solvent method. Typically, $0.2 \mathrm{~g}$ original commercial graphene oxide powder (NanJing JI Cang Nano Technology Co. Ltd. Model: JCGO-95-1-2.6) was dispersed in $200 \mathrm{~mL}$ ethanol solution in a sealed serum bottle 
under ultrasonic vibration for $12 \mathrm{~h}$. Then, the solution of $360 \mu \mathrm{L}$ TBOT in $50 \mathrm{~mL}$ ethanol was added dropwise into the above mixture with continuously stirring. The hydrolysis reaction was initiated upon exposure to air at $26^{\circ} \mathrm{C}$ for half a day. The resulting black product was filtered, and then the filtered $\mathrm{TiO}_{2} / \mathrm{GO}$ film was dried at $80{ }^{\circ} \mathrm{C}$ overnight. Finally, the anatase $\mathrm{TiO}_{2} / \mathrm{rGO}$ composite was obtained by cutting the film into pieces, which was transferred to the tube furnace, followed by annealment at $600{ }^{\circ} \mathrm{C}$ for $2 \mathrm{~h}$. For comparison, the control group of rGO was prepared under the same conditions.

\subsection{Synthesis of $\mathrm{TiN} / \mathrm{rGO}$ by microwave}

At first, the as-prepared dry $\mathrm{TiO}_{2} / \mathrm{GO}$ pieces were ground into a fine powder and loaded into a $\mathrm{SiC}$ coated graphite tube. Subsequently, the tube was placed in the microwave reactor (NanJing JieQuan Microwave Equipment Co. Ltd. Classic NJZ4-3 Microwave Oven). The reaction was rapidly heated to $1200{ }^{\circ} \mathrm{C}$ and held for $10 \mathrm{~min}$, then cooled to room temperature under $\mathrm{N}_{2}$ atmosphere.

\subsection{Synthesis of host material and sulfur composites}

The TiN/rGO-Sulfur (TiN/rGO-S) hybrid was synthesized via the classical melt-infiltration method: the prepared TiN/rGO powder was mixed uniformly with the commercial sublimed sulfur (Shanghai Aladdin Biochemical Technology Co., Ltd. Model: S106611) in a mass ratio of 40:60, and heated the mixture to $155^{\circ} \mathrm{C}$ for $12 \mathrm{~h}$. For comparison, $\mathrm{TiO}_{2} / \mathrm{rGO}$-Sulfur $\left(\mathrm{TiO}_{2} /\right.$ rGO-S) and rGO-Sulfur (rGO-S) composites with equal sulfur content were synthesized under the same conditions.

\subsection{Characterization of the samples}

The morphologies and element distributions of $\mathrm{rGO}, \mathrm{TiO}_{2} / \mathrm{GO}, \mathrm{TiN} / \mathrm{rGO}$, and their sulfurcontaining composites were confirmed using a scanning electron microscope (SEM, Hitachi SU-70) and transmission electron microscope (TEM, Tecnai G2 F20 S-TWIN, FEI, and $200 \mathrm{kV}$ ). The crystallographic structure of the samples were characterized by X-ray diffraction 
(XRD, Rigaku SmartLab, $40 \mathrm{kV}$ and $200 \mathrm{~mA}$ ), and the data was collected from $2 \theta=10-80^{\circ}$. The Raman spectra of the samples were measured by a Raman Microscope (RENISHAW invia, $\lambda=514.5 \mathrm{~nm})$. The sulfur content of the hybrids was identified by thermogravimetric analysis (Discovery TGA-55). The chemical interaction between the TiN/rGO and LiPSs was characterized by X-ray photoelectron spectroscopy (XPS, Microlab350). The specific surface area of the composites was confirmed by nitrogen adsorption-desorption analysis (Micromeritics Co. ASAP 2020).

\subsection{Cell assembly and electrochemical test}

In the case of cathode preparation, the as-prepared sulfur composites were mixed with carbon black and LA133 aqueous binder in a mass ratio of 80:15:5. The slurry was prepared using adequate ethylalcohol and $N$-methyl-2-pyrrolidone (NMP) as a solvent, then coated uniformly on aluminum foil with a scraping plate and dried at $60{ }^{\circ} \mathrm{C}$ in vacuum for half a day. Then, the aluminum foil was stamped into circular discs with a typical diameter of $16 \mathrm{~mm}$. In order to ensure consistent sulfur content, the control group $\mathrm{TiO}_{2} / \mathrm{rGO}-\mathrm{S}$ and $\mathrm{rGO}-\mathrm{S}$ were synthesized under the same processing conditions. All electrochemical tests were conducted on standard CR2016 type coin cells with the micro-porous polypropylene membrane as separators (Celgard2400, America). The entire assembly processes were conducted in a glove box filled with highly pure argon gas $\left(\mathrm{H}_{2} \mathrm{O}<0.10 \mathrm{ppm} ; \mathrm{O}_{2}<0.1 \mathrm{ppm}\right)$. The charge-discharge test was performed at a voltage window between 1.8 and $3.0 \mathrm{~V}\left(\mathrm{vs} . \mathrm{Li} / \mathrm{Li}^{+}\right)$on an automatic batteries test instrument (Land CT 2001A, model 5 V-10 mA). The capacities of the assembled button cells were calculated by the mass of sulfur $\left(1 \mathrm{C}=1670 \mathrm{~mA} \mathrm{~g}^{-1}\right)$. The sulfur loading of the sulfur electrode in Fig. $5 \mathrm{a}-\mathrm{e}$ is $1.2 \mathrm{mg} \mathrm{cm}{ }^{-2}$, and the electrolyte/sulfur ratio is $1 \mathrm{mg}$ sulfur: $15 \mu \mathrm{L}$ electrolyte. The corresponding electrochemical properties include cyclic voltammetry (CV) and electrochemical impedance spectra (EIS) of the cells were tested by CHI660D.

3. Results and discussion 
The preparation of $\mathrm{TiN} / \mathrm{rGO}-\mathrm{S}$ and $\mathrm{TiO}_{2} / \mathrm{rGO}-\mathrm{S}$ composite is outlined in Fig. 1 . A series of different ratio of TiN and rGO were perpared by mixing $0.2 \mathrm{~g} \mathrm{GO}$ with $0,180,360$, and $540 \mu \mathrm{L}$ tetrabutyl titanate (TBOT). The weight ratio of rGO and TiN was determined by TGA under $\mathrm{O}_{2}$ atmosphere (Fig. S1a). The weight ratio of $\mathrm{rGO}\left(\mathrm{W}_{\mathrm{rGO}}\right)$ in $\mathrm{TiN} / \mathrm{rGO}$ was calculated by $\mathrm{W}_{\mathrm{rGO}}$ - $\left(100 \%-\mathrm{W}_{\mathrm{rGO}}\right) \cdot 29 \%=\mathrm{W}$ Mass Loss. The mass of TiN increases by $29 \%$ upon conversion to $\mathrm{TiO}_{2}$ during the air heating process. Therefore, $\mathrm{rGO}$ contents in $\mathrm{TiN} / \mathrm{rGO}$ was prepared by mixing $0.2 \mathrm{~g}$ GO with $0,180,360$, and $540 \mu \mathrm{L}$ TBOT are $100,84.71,62.98$, and $48.92 \mathrm{wt} \%$, respectively. The corresponding TiN contents are $0,15.29,37.02$, and $51.08 \mathrm{wt} \%$, respectively. The rate capabilities of the four samples were investigated by discharging-charging mode at a range of discharging rates from 0.1 to $2 \mathrm{C}$ for each 10 cycles. As shown in Fig. S1b, the discharging capacity of TiN/rGO-S electrode increases with increasing TiN content from 0 to $37.02 \mathrm{wt} \%$. However, the discharging capacity reduced when the TiN contents further increased to $51.08 \mathrm{wt} \%$. Thus, the mixture ratio of $0.2 \mathrm{~g}$ GO with $360 \mu \mathrm{L}$ TBOT was selected for further studies. After the process of microwave-heating, the amorphous $\mathrm{TiO}_{2} / \mathrm{GO}$ hybrid (Fig. S2) was quickly converted into TiN/rGO nanocomposite in $10 \mathrm{~min}$. As shown in Fig. 2e and $\mathrm{f}$, the SEM images show that the TiN nano-crystalline are well-distributed and evenly anchored on the rGO sheets surface. The control group anatase $\mathrm{TiO}_{2} / \mathrm{rGO}$ hybrid was prepared by annealing the amorphous $\mathrm{TiO}_{2} / \mathrm{GO}$ composite at $600{ }^{\circ} \mathrm{C}$ for $2 \mathrm{~h}$ under $\mathrm{N}_{2}$ atmosphere. As shown in Fig. 2c and d, beside the smaller particle size, the morphology of $\mathrm{TiO}_{2} / \mathrm{rGO}$ is similar to the TiN/rGO. TGA analysis (Fig. S3) suggests that $\mathrm{TiO}_{2}$ content of $\mathrm{TiO}_{2} / \mathrm{rGO}$ hybrid is $38.73 \mathrm{wt} \%$. The other control group rGO was achieved by reduction of GO under the same heating conditions. The electrical conductivity of all samples (Fig. S4) was measured by a fourprobe resistivity measurement system. Unlike the curly and wrinkled surface of $\mathrm{TiO}_{2} / \mathrm{rGO}$ and TiN/rGO composites, the original rGO nano-sheets are thin and flat (Fig. 2a and b). Notably, the layered structure of the samples is largely preserved. 


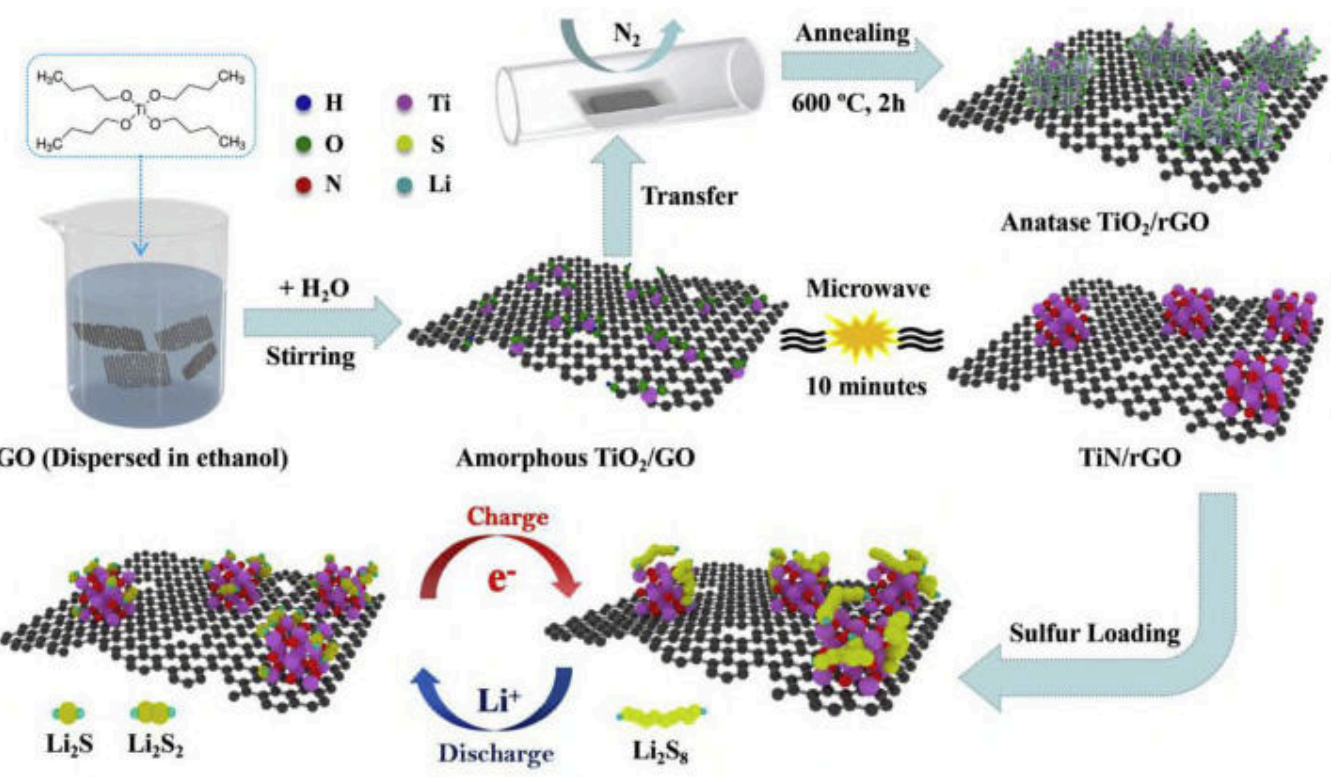

Fig. 1. A schematic illustration for the preparation of $\mathrm{TiN} / \mathrm{rGO}-\mathrm{S}$ and $\mathrm{TiO}_{2} / \mathrm{rGO}-\mathrm{S}$.
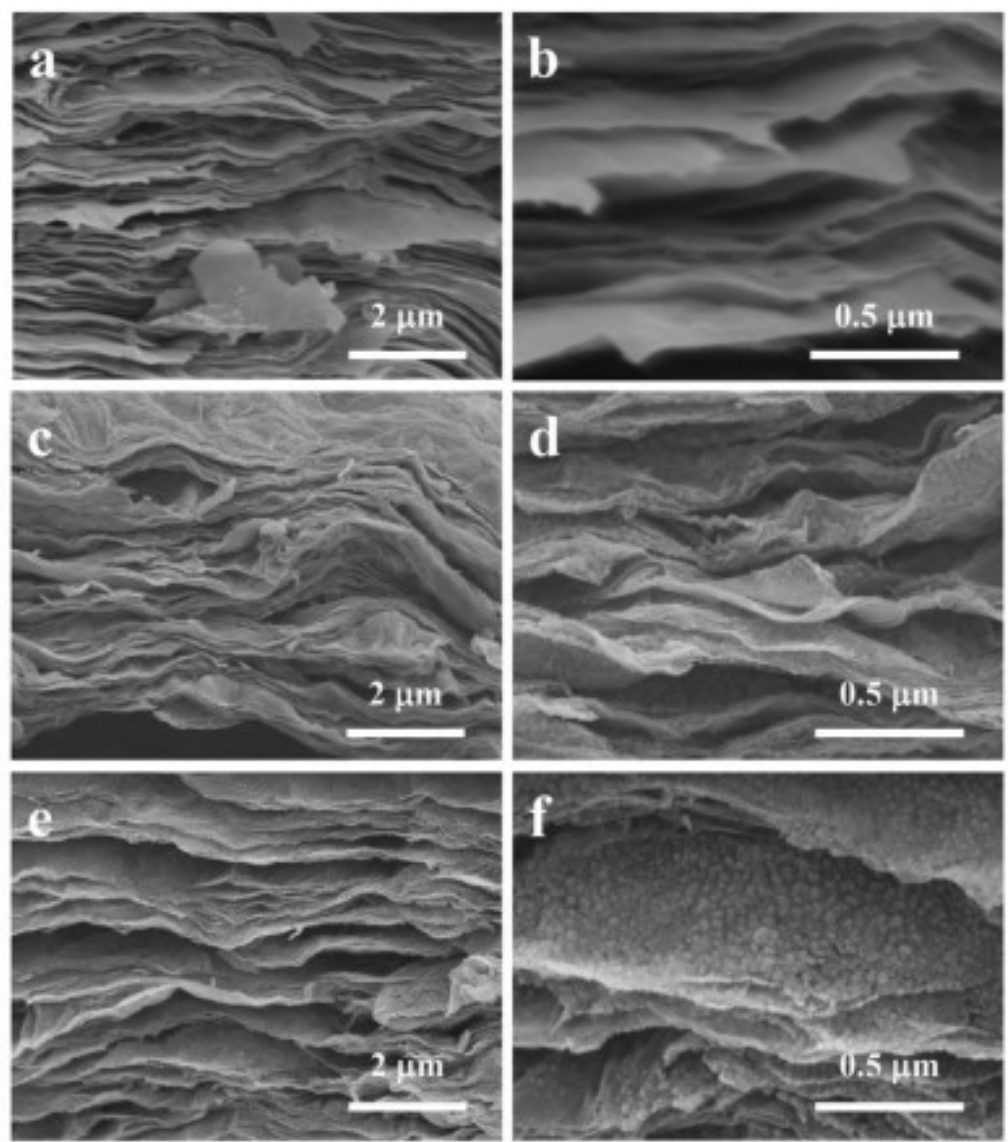
Fig. 2. (a,b) SEM images of pure graphene sheets; (c,d) SEM images of. anatase $\mathrm{TiO}_{2} / \mathrm{rGO}$; $(e, f)$ SEM images of TiN/rGO.

The structure and morphology of $\mathrm{TiO}_{2} / \mathrm{rGO}$ and $\mathrm{TiN} / \mathrm{rGO}$ composites were further analyzed by TEM. As shown in Fig. 3a and b, $\mathrm{TiO}_{2}$ nanoparticles with size distribution of 5-20 nm are evenly anchored on the surface of graphene, and no serious agglomeration is observed. The high-resolution TEM (HRTEM) images (Fig. 3c) display clear lattice fringes with values of ca. 0.242 and $0.351 \mathrm{~nm}$, corresponding to the $\mathrm{d}_{103}$-and $\mathrm{d}_{101}$-spacing of anatase $\mathrm{TiO}_{2}$, respectively [41]. The Fig. $3 \mathrm{~d}$ and e shows that the size of crystal grain grows to $10-50 \mathrm{~nm}$ after the microwave heating process. The spacing of the diffraction lattice fringe displayed in Fig. $3 f$ are ca. $0.212 \mathrm{~nm}$, which is consistent with the $\mathrm{d}_{200}$-spacing of TiN. The enhanced bonding between $\mathrm{TiO}_{2}$ and rGO nanosheets may benefit from a great quantity of oxygen-containing function groups on the surface of precursor GO. High cohesion between the amorphous $\mathrm{TiO}_{2}$ and GO can also facilitate the transformation of amorphous $\mathrm{TiO}_{2} / \mathrm{GO}$ to $\mathrm{TiN} / \mathrm{rGO}$ composite under microwave reduction.
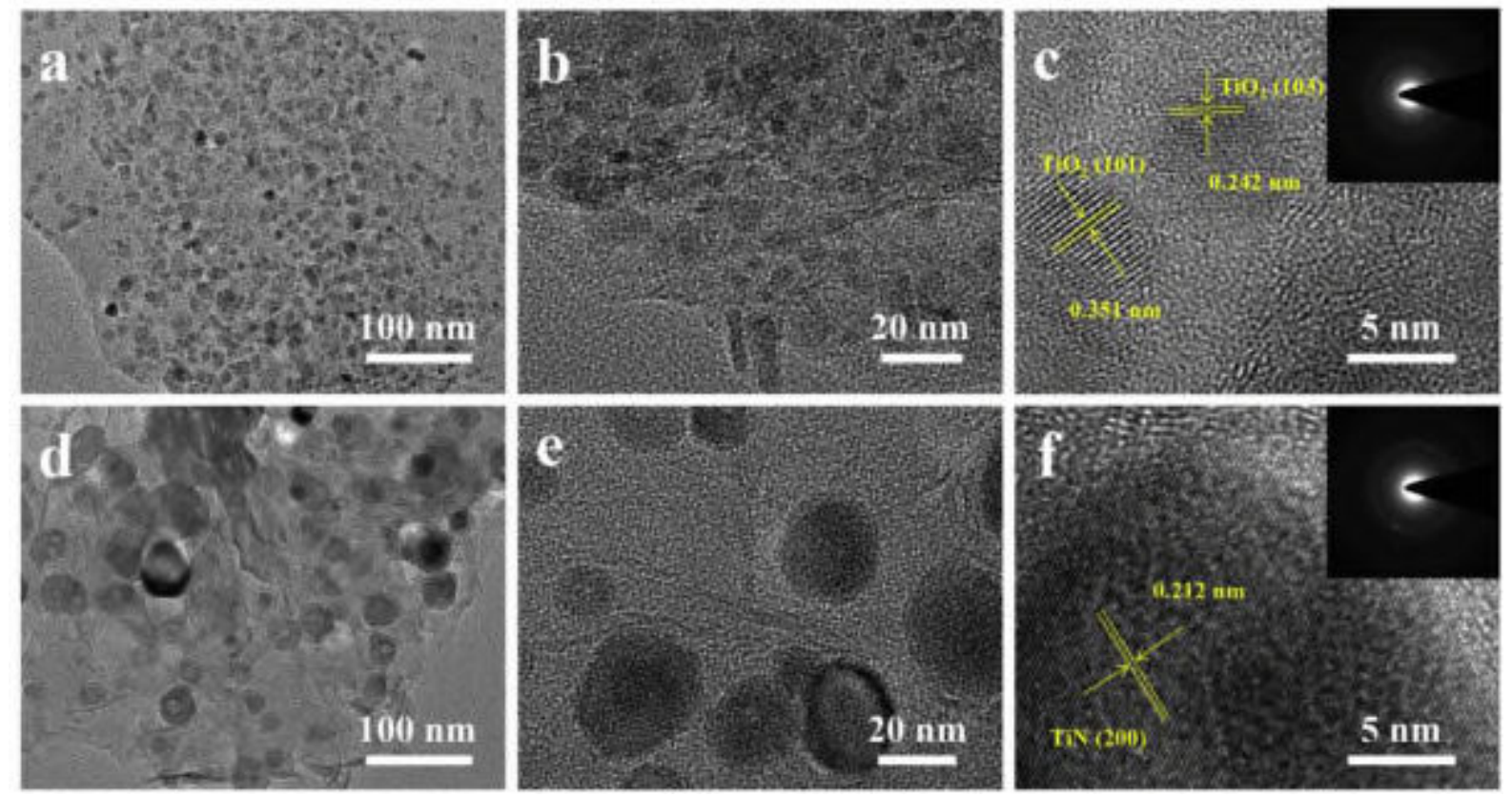

Fig. 3. (a-c) low magnification and high resolution TEM of the anatase $\mathrm{TiO}_{2} / \mathrm{rGO}$; (d-f) low magnification and high resolution TEM of the TiN/rGO. 
The crystal structure of commercial $\mathrm{GO}$, as-prepared $\mathrm{rGO}, \mathrm{TiO}_{2} / \mathrm{rGO}$ and $\mathrm{TiN} / \mathrm{rGO}$ composite was confirmed through XRD. Fig. 4 a shows the XRD patterns of the commercial GO nanosheets, an intensive diffraction peak appears at approx. $11^{\circ}$ corresponding to the $(001)$ diffraction of GO. A peak shift is observed toward the high angle side (ca. $26^{\circ}$ ) after microwave reduction, which is due to the (002) diffraction of $\mathrm{rGO}$ [42]. The typical peaks located at $36.65^{\circ}$, $42.57^{\circ}, 61.78^{\circ}, 74.02^{\circ}$ and $77.91^{\circ}$ in the XRD patterns are assigned to the (111), (200), (220), (311), and (222) planes of standard TiN (PDF \# 87-0628), which indicates that the $\mathrm{TiO}_{2} / \mathrm{GO}$ precursor is completely converted into $\mathrm{TiN} / \mathrm{rGO}$ in high purity and crystallization $[43,44]$. The phase of $\mathrm{TiO}_{2} / \mathrm{rGO}$ was also confirmed by XRD, with all diffraction peaks being consistent with anatase $\mathrm{TiO}_{2}$ (PDF \# 73-1764). Meanwhile, the diffraction of rGO is detected in the $\mathrm{TiO}_{2} / \mathrm{rGO}$ and $\mathrm{TiN} / \mathrm{rGO}$ composites, indicating that $\mathrm{TiN}$ and $\mathrm{TiO}_{2}$ nanoparticles are closely integrated with rGO. 

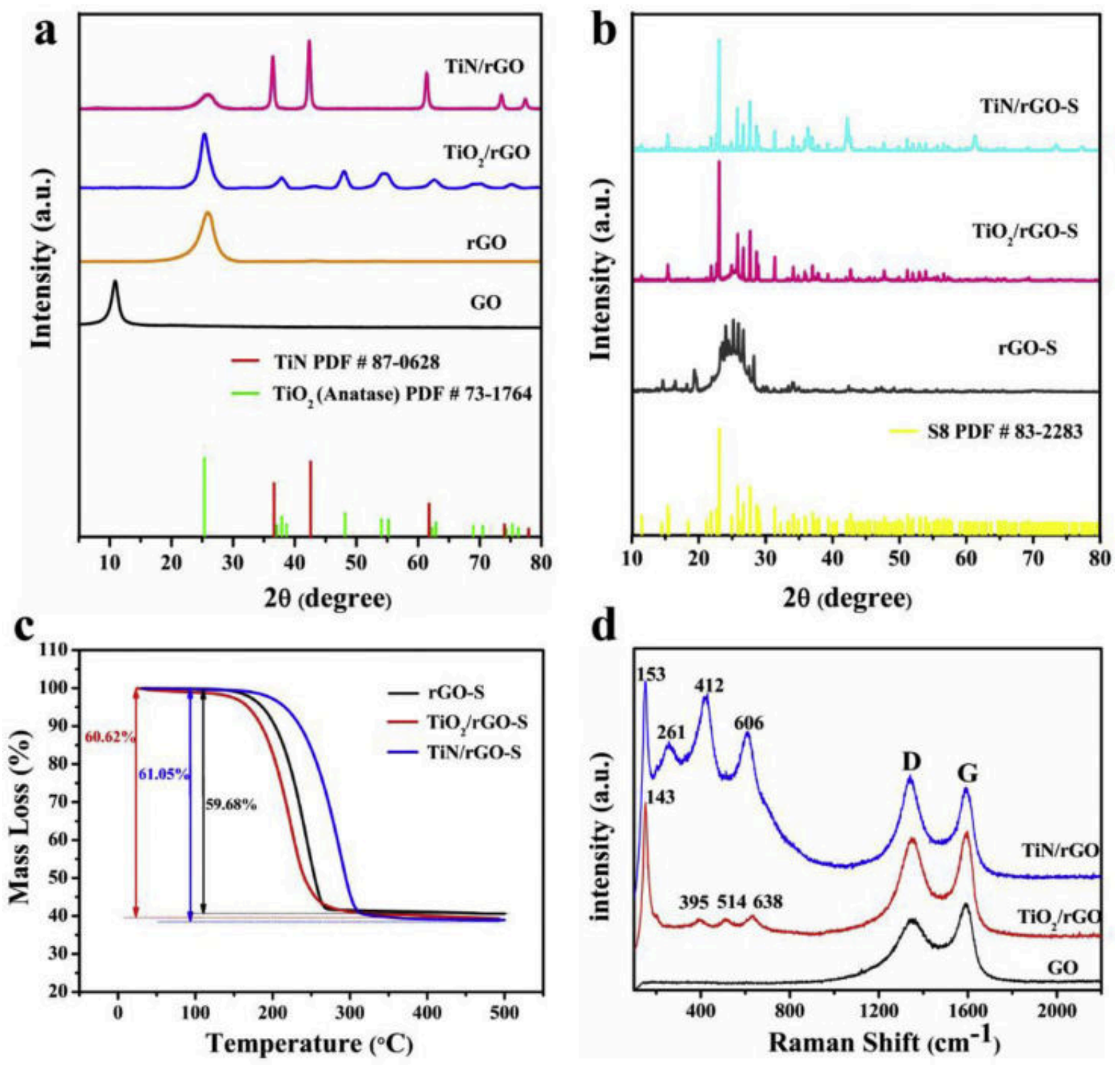

Fig. 4. (a) XRD pattern of $\mathrm{GO}, \mathrm{rGO}, \mathrm{TiO}_{2} / \mathrm{rGO}$ and $\mathrm{TiN} / \mathrm{rGO}$, green and red drop lines correspond to anatase $\mathrm{TiO}_{2}$ (PDF \# 73-1764) and TiN (PDF \# 87-0628); (b) XRD pattern of rGO-S, $\mathrm{TiO}_{2} / \mathrm{rGO}-\mathrm{S}$ and TiN/rGO-S, yellow drop lines correspond to sulfur (PDF \# 832283); (c) TG curves of rGO-S, $\mathrm{TiO}_{2} / \mathrm{rGO}-\mathrm{S}$ and TiN/rGO-S; (d) Raman spectra of GO, $\mathrm{TiO}_{2} / \mathrm{rGO}$ and $\mathrm{TiN} / \mathrm{rGO}$. 

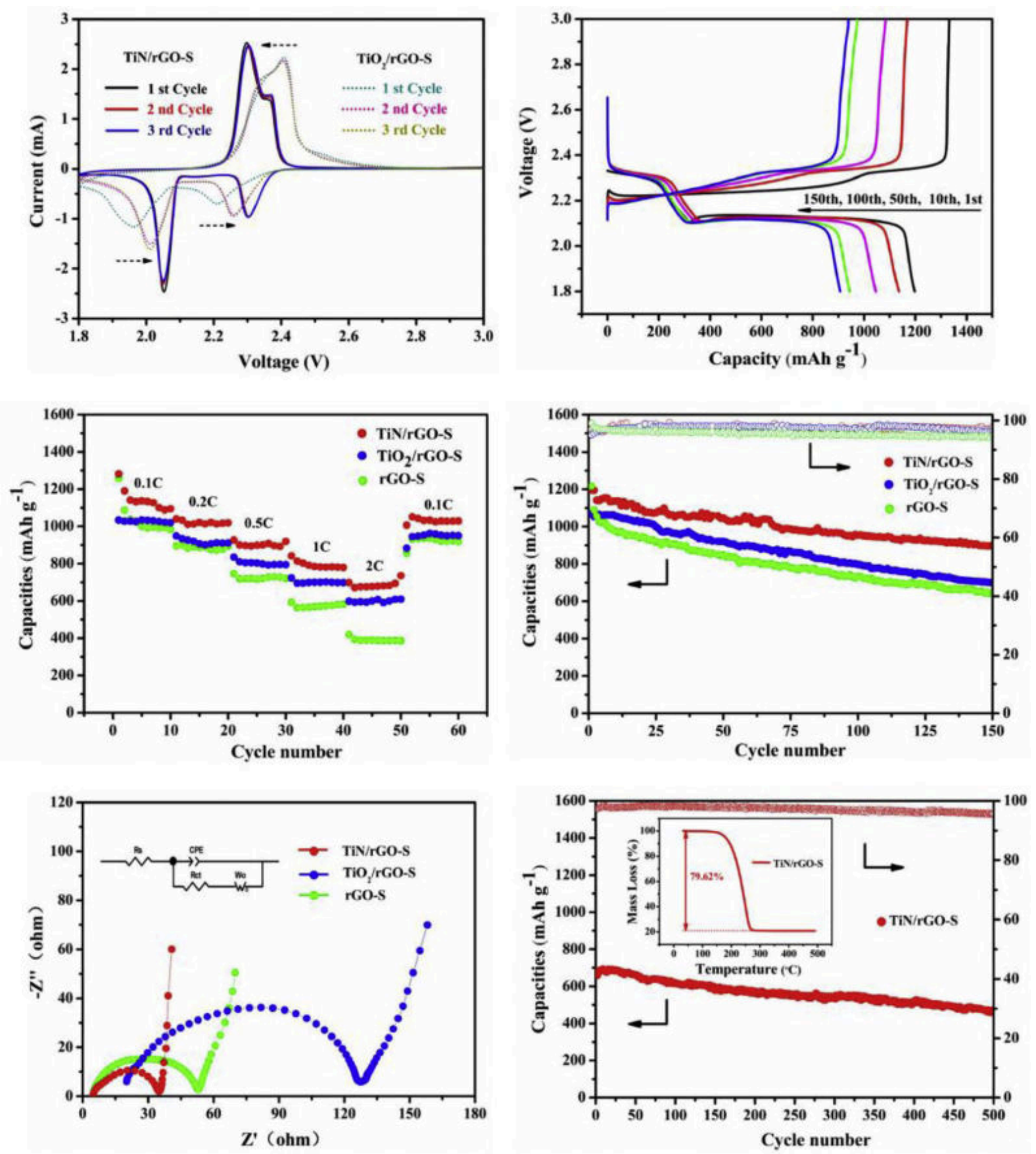

Fig. 5. Electrochemical performance. (a) $\mathrm{CV}$ profiles of $\mathrm{TiO}_{2} / \mathrm{rGO}-\mathrm{S}$ and $\mathrm{TiN} / \mathrm{rGO}-\mathrm{S}$ cathodes; (b) charge-discharge profiles of TiN/rGO-S cathode over different cycles at a current rate of $0.1 \mathrm{C}$; (c) rate capacity, (d) cycling performance at $0.1 \mathrm{C}$ and (e) EIS spectra of rGO-S, $\mathrm{TiO}_{2} / \mathrm{rGO}-\mathrm{S}$ and TiN/rGO-S cathodes before cycling; (f) cycling performance of

TiN/rGO-S cathode (with the sulfur content of $79.62 \%$ wt.) at a current rate of $1 \mathrm{C}$.

The Raman spectra of pure $\mathrm{GO}, \mathrm{TiO}_{2} / \mathrm{rGO}$ and $\mathrm{TiN} / \mathrm{rGO}$ hybrids are depicted in Fig. $4 \mathrm{~d}$. In the case of $\mathrm{TiO}_{2} / \mathrm{rGO}$ composite, a strong Raman scattering peak is observed at $143 \mathrm{~cm}^{-1}$ due to 
$E_{\mathrm{g}}$ vibration modes of anatase. Other peaks observed at approx. 385, 514, and $638 \mathrm{~cm}^{-1}$, which are related to the typical vibrational modes of anatase [45]. Furthermore, four peaks at approx. 153, 261, 412, and $606 \mathrm{~cm}^{-1}$ are ascribed to TiN [46]. Notably, all samples exhibit a pair of adjacent intensive peaks at approx. 1350 and $1600 \mathrm{~cm}^{-1}$, which correspond to the D- and Gband of GO and rGO, respectively. The $\mathrm{D}$ (disorder and defects) band commonly corresponds to the $k$-point phono on $\mathrm{A}_{1 \mathrm{~g}}$ symmetry, and $\mathrm{G}$ (graphitic) band is ascribed to the in-plane stretching motion of symmetrical $\mathrm{sp}^{2} \mathrm{C}-\mathrm{C}$ bond [47]. Accordingly, the TiN/rGO sample occupies the highest $I_{D} / I_{G}$ intensity ratios (1.07), followed by $\mathrm{TiO}_{2} / \mathrm{rGO}(0.97)$ and pure GO (0.85). Therefore, TiN doped graphene contains more defects than $\mathrm{TiO}_{2}$ doped graphene and untreated $\mathrm{GO}$, due to decomposition of the abundant oxygen-containing groups of the $\mathrm{GO}$ during the microwave reduction process. Fang et al. investigated the interaction between $\mathrm{Li}$ and defective graphene via first-principles calculations [48]. Results of this study demonstrate that the presence of vacancy defects can enhance the adsorption energy of $\mathrm{Li}$ in the region near the defect, because Li atom is easier to adsorb on the hollow site. Previous studies have also shown that the vacancy defects can physically accommodate the active materials sulfur and LiPSs and facilitate electrolyte infiltration [49]. On the other hand, the defects in the TiN/rGO composite, such as sp3 carbon and vacancy holes, can affect its conductivity to some extent. Therefore, the electrical conductivity of $\mathrm{TiO}_{2} / \mathrm{rGO}$, TiN/rGO, rGO (prepared in a tube furnace at $600{ }^{\circ} \mathrm{C}$ ), and $\mathrm{rGO}$ (prepared in a microwave reactor at $1200^{\circ} \mathrm{C}$ ) were measured using the 4point probes resistivity measurement system. As shown in Fig. S4, the different reduction processes have little influence on the electrical conductivity of rGO. Thus, we can assume that the defects in $\mathrm{TiO}_{2} / \mathrm{rGO}$ and $\mathrm{TiN} / \mathrm{rGO}$ have little impact on their electrical conductivity. Moreover, reports have shown that graphene's defects can facilitate the heteroatoms doping, which in turn contributes to improved conductivity [49]. 
Eq. (1) briefly describes the transformation process from amorphous $\mathrm{TiO}_{2} / \mathrm{GO}$ to crystalline TiN/rGO under microwave heating under $\mathrm{N}_{2}$ atmosphere.(1)2 $\mathrm{TiO}_{2}+4 \mathrm{C}+\mathrm{N}_{2} \rightarrow 2 \mathrm{TiN}+4 \mathrm{CO}$ $\uparrow$ In contrast with $\mathrm{NH}_{3}, \mathrm{~N}_{2}$ was selected as the nitrogen source due to safety and cost consideration. Generally, TiN formation is difficult via gas/solid phase reactions with conventional heating methods since the strong binding of the N-N covalent is very robust [50,51]. Under microwave irradiation, however, TiN/rGO composite is easily obtained in good crystallinity and dispersion at $1200{ }^{\circ} \mathrm{C}$ in $10 \mathrm{~min}$. It is widely believed that the lower initial reaction temperature and accelerated diffusion rate attributed to the dual thermal and nonthermal effects are promoted by microwave heating [52].

The sulfur content was determined by TG analysis, which was approx. $60 \%$ for rGO-S, $\mathrm{TiO}_{2} / \mathrm{rGO}-\mathrm{S}$ and TiN/rGO-S (Fig. 4c). All X-ray diffraction peaks are in accordance with the standard cards of pure TiN (PDF \# 87-0628), $\mathrm{TiO}_{2}$ (PDF \# 73-1764) and element sulfur (PDF \# 83-2283), indicating that $\mathrm{TiN}$ and $\mathrm{TiO}_{2}$ are stable after sulfur incorporation (Fig. 4b). SEM images of TiN/rGO-S are shown in Fig. S5. Characterized by elemental maps, the sulfur nanoparticles have high quality dispersion on the surface of TiN/rGO composite.

To demonstrate the enhanced polysulfide adsorption ability of the as-prepared TiN/rGO-S, three samples, rGO-S, $\mathrm{TiO}_{2} / \mathrm{rGO}-\mathrm{S}$ and TiN/rGO-S, were respectively used as cathodes and their electrochemical properties systematically evaluated using CR2016 coin cells. The CV profiles of the first three cycles (Fig. 5a) for both $\mathrm{TiO}_{2} / \mathrm{rGO}-\mathrm{S}$ and TiN/rGO-S electrodes possess a similar shape. Two representative cathodic peaks at $2.19-2.41 \mathrm{~V}$ and $1.91-2.10 \mathrm{~V}$ are considered as the two stepwise reduction reactions of elemental sulfur $\left(\mathrm{S}_{8}\right)$. The highpotential cathodic peak stems from the ring open reduction of $\mathrm{S}_{8}$ to long chain LiPSs $\left(\mathrm{Li}_{2} \mathrm{~S}_{\mathrm{x}}\right.$, $4 \leq \mathrm{x}<8$ ), and the low-potential cathodic peak is known to be further reduced from LiPSs to insoluble $\mathrm{Li}_{2} \mathrm{~S}_{2}$ and $\mathrm{Li}_{2} \mathrm{~S}$ [53]. 
Furthermore, two reduction peaks potentials upshift from $\mathrm{TiO}_{2} / \mathrm{rGO}-\mathrm{S}$ to TiN/rGO-S by 39 $89 \mathrm{mV}$ are clearly observed, indicating that the rate of electrochemical process is slower on the hybrid surface of $\mathrm{TiO}_{2} / \mathrm{rGO}$ than $\mathrm{TiN} / \mathrm{rGO}$. The extra electron transportation process on the $\mathrm{TiO}_{2} / \mathrm{rGO}$ interface causes additional energy loss, leading to a higher negative potential. Whereas, the oxidation peak of the TiN/rGO-S electrode $(2.31 \mathrm{~V})$ is lower than that of $\mathrm{TiO}_{2} / \mathrm{rGO}-\mathrm{S}(2.41 \mathrm{~V})$. The obvious negative shift of the oxidation peak of TiN/rGO-S cathode implies that the TiN can enhance the rate of the oxidation process of insoluble short-chain to soluble long-chain LiPSs [54]. Meanwhile, the redox peaks of rGO-S (Fig. S6) are between the $\mathrm{TiO}_{2} / \mathrm{rGO}-\mathrm{S}$ and $\mathrm{TiN} / \mathrm{rGO}-\mathrm{S}$. The substantial reduction of anodic peaks and increase in cathodic peaks of TiN/rGO-S cathode indicates that the reaction kinetics of sulfur is significantly improved in the TiN/rGO composite.

The discharging-charging profiles of the TiN/rGO-S cathode (Fig. $5 \mathrm{~b}$ ) were conducted at $0.1 \mathrm{C}$ from 1st to 150th cycles. The discharging curves consist of two platforms at around 2.1 and $2.3 \mathrm{~V}$, respectively. The short platform at $2.3 \mathrm{~V}$ corresponds to the transformation from longchain to short-chain LiPSs, while, the flatter and longer platform at $2.1 \mathrm{~V}$ relates to the conversion of short-chain LiPSs to insoluble discharge products $\left(\mathrm{Li}_{2} \mathrm{~S} / \mathrm{Li}_{2} \mathrm{~S}_{2}\right)$, which are in agreement with the $\mathrm{CV}$ profiles [55]. The rate capabilities of the TiN/rGO-S, $\mathrm{TiO}_{2} / \mathrm{rGO}-\mathrm{S}$ and rGO-S electrodes were measured by discharging-charging mode at a range of discharging rates from 0.1 to $2 \mathrm{C}$ for each 10 cycles (Fig. 5c). The as-prepared TiN/rGO-S cathodes exhibit much higher capacity than those of the $\mathrm{TiO}_{2} / \mathrm{rGO}-\mathrm{S}$ electrodes over the entire discharging-charging process. Average reversible discharge capacities of 1143, 1020, 904, 794 and $687 \mathrm{mAh} \mathrm{g}^{-1}$ are obtained at $0.1,0.2,0.5,1$ and $2 \mathrm{C}$ for TiN/rGO-S cathode in each 10 cycles, respectively. Notably, a stable average reversible specific capacity of $1031 \mathrm{mAh} \mathrm{g}^{-1}$ is retained once the discharging-charging rate is switched back to $0.1 \mathrm{C}$ after 50 cycles under a range of different current rates, indicating well stable reversible capability [56]. In contrast, the specific capacity 
of $\mathrm{TiO}_{2} / \mathrm{rGO}-\mathrm{S}$ electrode at $0.1,0.2,0.5,1$ and $2 \mathrm{C}$ rates are $1028,918,803,701$ and $600 \mathrm{mAh}$ $\mathrm{g}^{-1}$, respectively. The $\mathrm{TiO}_{2} / \mathrm{rGO}-\mathrm{S}$ exhibits obviously lower discharge capacities than TiN/rGO-S electrode mainly due to inferior electronic conductivity, which leads to poor active material utilization ratio [57]. The capacity of the rGO-S cathodes shows a dramatic decrease with increasing current density. The average capacity of rGO-S cathode remains with only 391 $\mathrm{mAh} \mathrm{g}^{-1}$ at $2 \mathrm{C}$.

In addition, the discharging and charging voltage profiles of the TiN/rGO-S cathode for the first cycle at the series current densities from $0.1 \mathrm{C}$ to $2 \mathrm{C}$ were measured (Fig. S7). The voltage hysteresis $(\Delta E)$ is larger at higher current rate compared to lower rate due to polarization. However, all the curves maintain two complete and flat plateaus, indicating the excellent electrochemical reaction kinetics of TiN/rGO-S composite. The cycling stability of the TiN/rGO-S, $\mathrm{TiO}_{2} / \mathrm{rGO}-\mathrm{S}$ and $\mathrm{rGO}-\mathrm{S}$ cathodes was measured by long-term galvanostatic discharging and charging test at $0.1 \mathrm{C}$. As shown in Fig. 5d, the TiN/rGO-S electrode demonstrates a high initial discharging capacity of $1197.6 \mathrm{mAh} \mathrm{g}^{-1}$, where the reversible capacity of $888.7 \mathrm{mAh} \mathrm{g}^{-1}$ is retained after 150 cycles. By increasing the current density to $0.2 \mathrm{C}$, the TiN/rGO-S electrode maintains a high initial discharging capacity of $1136 \mathrm{mAh} \mathrm{g}^{-1}$ and reversible capacity of $831 \mathrm{mAh} \mathrm{g}^{-1}$ after 200 cycles (Fig. S8), indicating good long-term cycling stability. In the case of the rGO-S electrode, the specific discharge capacity is comparable to that of TiN/rGO-S in the first cycle at $0.1 \mathrm{C}\left(1216 \mathrm{mAh} \mathrm{g}^{-1}\right)$, but decays drastically in subsequent cycles. The low cycle stability of rGO-S is mainly due to the weak physical adsorption between $\mathrm{rGO}$ and LiPSs. In contrast, the $\mathrm{TiO}_{2} / \mathrm{rGO}-\mathrm{S}$ cathode shows a significantly lower initial discharge capacity $\left(1070 \mathrm{mAh} \mathrm{g}^{-1}\right)$ due to low conductivity, but it possesses enhanced cyclic stability compared to rGO-S in the later cycles. This phenomenon can primarily be attributed to the $\mathrm{TiO}_{2}$ nanoparticles, which can provide an extra chemical bond for the polar LiPSs [57]. 
Electrochemical impedance spectrum (EIS) test before cycling was conducted to investigate the internal electrochemical reaction kinetics of the three button cells. As depicted in Fig. 5e, the semicircle at high frequencies are related to the charge transfer resistance $(R c t)$ at the electrolyte/electrode interface, accompanying an oblique line at the low frequency region representing the ion diffusion [58]. The $R c t$ value of TiN/rGO-S cathode (31.7 $\Omega$ ) is smaller than that of the rGO-S $(47.3 \Omega)$ and $\mathrm{TiO}_{2} / \mathrm{rGO}-\mathrm{S}(113.3 \Omega)$ electrode, indicating a faster charge transfer and enhanced surface reaction between TiN and LiPSs. Fig. S9 exhibits the EIS plots of the TiN/rGO-S, $\mathrm{TiO}_{2} / \mathrm{rGO}-\mathrm{S}$ and $\mathrm{rGO}-\mathrm{S}$ cathodes after 20 cycles at the full charged state. The high-frequency semicircles of three samples are clearly reduced compared to those of the corresponding fresh cells displayed in Fig. 5e, suggesting enhanced charge transport, rearrangement of the active material, and better electrolyte infiltration after the initial cycles. The SEM images of the cycled TiN/rGO electrode (Fig. S10) reveals that the structural integrity of the cathode remains intact.

Furthermore, high areal sulfur loading is critical to satisfy the requirement for actual application. Accordingly, the cycling performance of TiN/rGO-S electrodes with approx. 80\% sulfur content and $2 \mathrm{mg} \mathrm{cm}^{-2}$ areal loading are presented in Fig. 5f. The electrodes show a high discharging capacity of $700 \mathrm{mAh} \mathrm{g}^{-1}$ at $1 \mathrm{C}$ rate after the activation processes of initial three circles, and retain a reversible capacity of $460 \mathrm{mAh} \mathrm{g}^{-1}$ after 500 cycles.

To show the strong anchoring ability of the TiN/rGO for LiPSs, the equivalent total surface area of $\mathrm{rGO}, \mathrm{TiO}_{2} / \mathrm{rGO}$ and $\mathrm{TiN} / \mathrm{rGO}$ composites were added to a solution of $\mathrm{Li}_{2} \mathrm{~S}_{\mathrm{x}}$ in DOL/DEM (ratio of 1:1 by vol) and allowed to stand for $24 \mathrm{~h}$. The total surface area and pore size distribution of as-added powders were determined by nitrogen adsorption/desorption isotherms measurements (Figs. S11 and S12). As shown in Fig. 6a, the mixture with TiN/rGO composite becomes colorless, implying a strong absorption between $\mathrm{Li}_{2} \mathrm{~S}_{\mathrm{x}}$ and $\mathrm{TiN}$. While, the $\mathrm{TiO}_{2} / \mathrm{rGO}$-containing solution changes color from dark brown to pale yellow. In contrast, upon 
contact with $\mathrm{rGO}$, the $\mathrm{Li}_{2} \mathrm{~S}_{\mathrm{x}}$ solution still displays a quite conspicuous light brown color, similar to the original state.
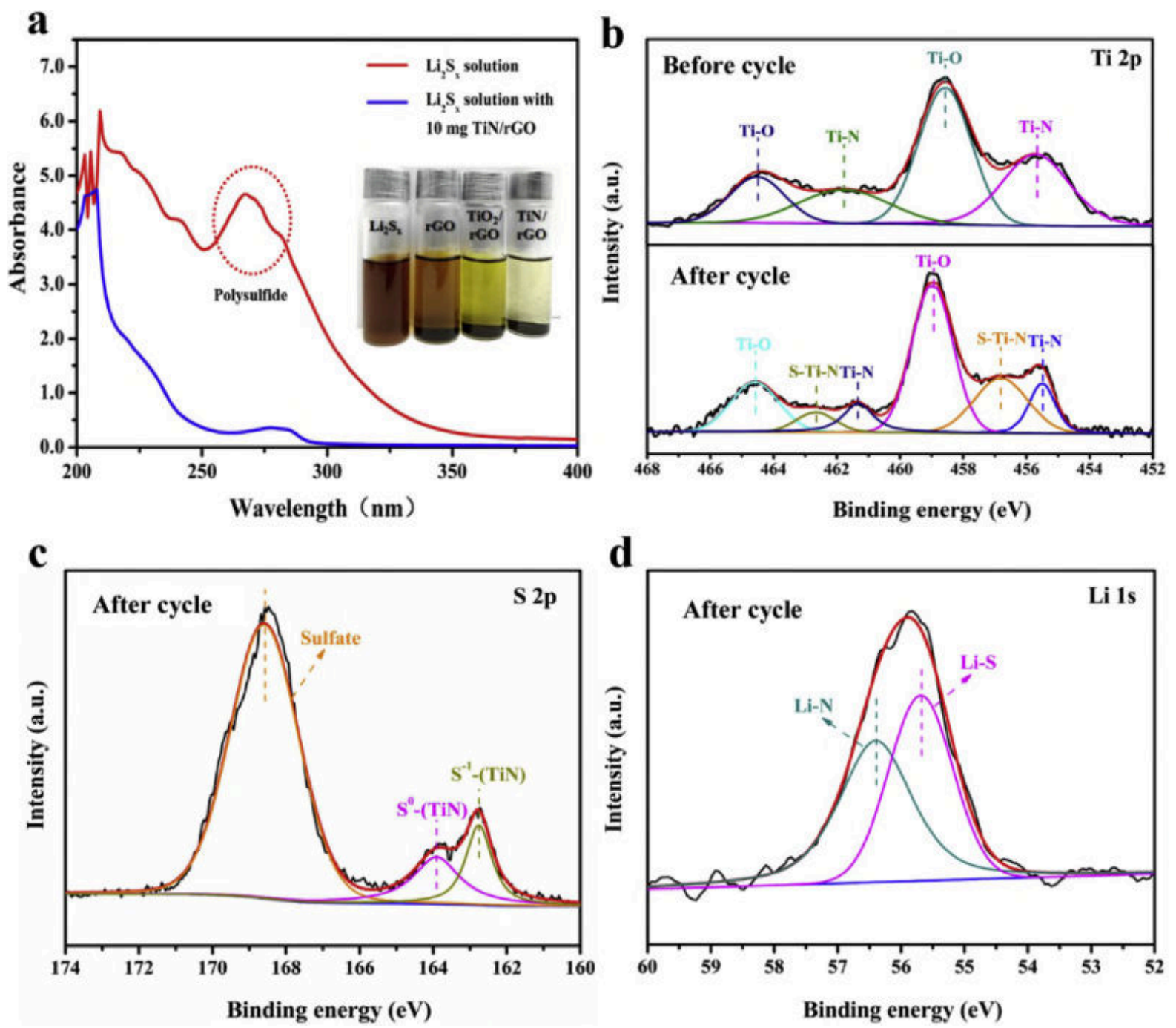

Fig. 6. (a) Ultraviolet/visible adsorption spectra of a $\mathrm{Li}_{2} \mathrm{~S}_{\mathrm{x}}$ solution before and after the addition of TiN/rGO, inset image shows a photograph of a $\mathrm{Li}_{2} \mathrm{~S}_{\mathrm{x}}$ solution before and after the addition of various host material; (b) XPS spectra corresponding to Ti $2 \mathrm{P}$ of TiN/rGO electrode before and after 100 cycles at $0.1 \mathrm{C}$ (1.8 V discharged state); (c) S 2P and (d) Li 1S of TiN/rGO electrode after lithiation (100 cycles at $0.1 \mathrm{C}, 1.8 \mathrm{~V}$ discharged state). 
The ultraviolet/visible absorption test was conducted to confirm the $\mathrm{Li}_{2} \mathrm{~S}_{\mathrm{x}}$ adsorption effect of TiN/rGO. The large absorption band at approx. $280 \mathrm{~nm}$ is attributed to the presence of $\mathrm{S}_{4}{ }^{2-} / \mathrm{S}_{6}{ }^{2-}$ species [59]. Upon mixing with TiN/rGO, a clear decrease in peak intensity is observed, owing to the significant affinity of polysulfides toward TiN edge sites. XPS measurements were conducted to further confirm the chemical interaction between TiN/rGO and LiPSs. LiPSs is known to show a Lewis basic characteristic, while Ti atoms exposed to the rGO surface with unoccupied orbitals act as Lewis acid sites, thus, $\mathrm{TiO}_{2} / \mathrm{TiN}$ and LiPSs can act as Lewis acid and base to contribute electrons to the Ti-S covalence, respectively. The dispersion interaction energy between $\mathrm{TiO}_{2} / \mathrm{TiN}$ and $\mathrm{Li}_{2} \mathrm{~S}_{4}$ with a value of -3.47 and $-2.94 \mathrm{eV}$, is superior to the adsorption energies on known adsorbents such as $\mathrm{C}_{3} \mathrm{~N}_{4}(-2.42 \mathrm{eV})$ and black phosphorus (Fig. $\mathrm{S} 13$ shows the comparison of $\mathrm{Li}_{2} \mathrm{~S}_{4}$ adsorption energies of $\mathrm{TiO}_{2} / \mathrm{TiN}$ and other absorbent materials).

The high-resolution XPS spectra corresponding to Ti 2P of TiN/rGO electrode before and after 100 cycles at $0.1 \mathrm{C}(1.8 \mathrm{~V}$ discharged state) are shown in Fig. $6 \mathrm{~b}$. Before cycling, the Ti 2p3/2 peak and Ti 2p1/2 peak of 455.6 and $461.3 \mathrm{eV}$ are related to $\mathrm{N}-\mathrm{Ti}$ bond for TiN $[43,60]$. Meanwhile, the Ti $2 \mathrm{p} 3 / 2$ peak and Ti $2 \mathrm{p} 1 / 2$ peak of 458.5 and $464.3 \mathrm{eV}$ are ascribed to the TiO bond of oxynitride [61]. The presence of oxynitride is due to the slight oxidation passivation layer on the surface of TiN nanoparticles when exposed to the air [62]. Reports have shown that TiN thin films with low levels of oxygen content reveal a partial metallic property, indicating that the oxynitride layer on the surface of TiN nanoparticles possesses good electrical conductivity [63]. After cycling, no obvious changes in the Ti 2P peaks are observed, except for two new peaks appearing at 456.8 and $462.6 \mathrm{eV}$, which corresponds to the $\mathrm{S}-\mathrm{Ti}-\mathrm{N}$ bond, confirming the adsorption properties of TiN and LiPSs [64]. In the N 1S spectrum, before cycling, the main peaks at 397.3 and $396.5 \mathrm{eV}$ are observed corresponding to $\mathrm{TiN}$ and oxynitride, respectively, which are consistent with the Ti 2P data (Fig. S14). Furthermore, after 
100 cycles at $0.1 \mathrm{C}$, an additional peak at $400.8 \mathrm{eV}$ is observed, originating from the $\mathrm{S}-\mathrm{N}-\mathrm{Ti}$ bond [65]. Upon covalent bond formation the original two peaks shift toward lower binding energies owing to the similar electronegativity of sulfur and nitrogen atoms [44]. In addition, two peaks corresponding to $\mathrm{Li}-\mathrm{S}\left(\mathrm{S}^{-1}\right)$ and bridged $\mathrm{S}-\mathrm{S}\left(\mathrm{S}^{0}\right)$ bond are detected in the $\mathrm{S} 2 \mathrm{p}$ spectrum (Fig. 6c) after lithiation [66]. Similarly, a broad peak in the Li 1S spectrum of the electrode (Fig. 6d) is further divided into two peaks at 55.6 and $56.4 \mathrm{eV}$, which are related to the $\mathrm{Li}-\mathrm{S}$ and $\mathrm{Li}-\mathrm{N}$ bond, respectively [67]. For comparative analysis, the XPS spectra (Fig. S15) of $\mathrm{Ti} 2 \mathrm{P}$ of $\mathrm{TiO}_{2} / \mathrm{rGO}-\mathrm{S}$ electrode before and after 100 cycles at $0.1 \mathrm{C}$ and $\mathrm{S} 2 \mathrm{P}$ of $\mathrm{TiO}_{2} / \mathrm{rGO}-$ $\mathrm{S}$ electrode after lithiation were examined. This suggests that $\mathrm{Ti}-\mathrm{S}$ and $\mathrm{Li}-\mathrm{N}$ bonds exist between TiN nanoparticles and LiPSs endowing the TiN/rGO composite with high capacity of sulfur utilization. Moreover, recent studies have shown that TiN efficiency accelerates the decomposition of $\mathrm{Li}_{2} \mathrm{~S}_{8}$, which is not observed on $\mathrm{TiO}_{2}$ surface [67]. The electrical conductivity of TiN at room temperature is approx. $4.0 \times 10^{6} \mathrm{~S} \mathrm{~m}^{-1}$, which is considerably greater that of $\mathrm{TiO}_{2}\left(<10^{-10} \mathrm{~S} \mathrm{~m}^{-1}\right)$ [68]. In combination with its strong polysulfides adsorption ability, high electrical conductivity, and acceleration mechanism to $\mathrm{Li}_{2} \mathrm{~S}_{8}$, the prepared $\mathrm{TiN} / \mathrm{rGO}$ based cathode enables $\mathrm{Li}-\mathrm{S}$ batteries with significantly reduced potential barrier and prolonged cycling stability.

The comparison of the adsorption mechanism of $\mathrm{rGO}-\mathrm{S}, \mathrm{TiO}_{2} / \mathrm{rGO}-\mathrm{S}$ and $\mathrm{TiN} / \mathrm{rGO}-\mathrm{S}$ composites is depicted in Fig. 7. Although rGO has favorable conductivity, which facilitates the electron transfer, the liquid LiPSs can easily diffuse into the electrolyte from rGO-S cathode due to its non-polar property. Additionally, the different surface energies between rGO and deposited $\mathrm{Li}_{2} \mathrm{~S}$ nuclei increase the nucleation barrier, further increasing power wastage. On the contrary, the $\mathrm{TiO}_{2} / \mathrm{rGO}-\mathrm{S}$ composite possesses desirable chemical absorption toward LiPSs. Nonetheless, its poor electrical conductivity incompatible with the rGO nanosheets impedes the electron transfer between the interfaces. As for TiN/rGO-S, efficient charge transport, 
strong chemisorption and electrochemical catalysis can be simultaneously satisfied, which results in enhanced electrochemical kinetics. Compared with other similar sulfur host materials summarized in Table S2, TiN/rGO can effectively improve the cyclic stability.
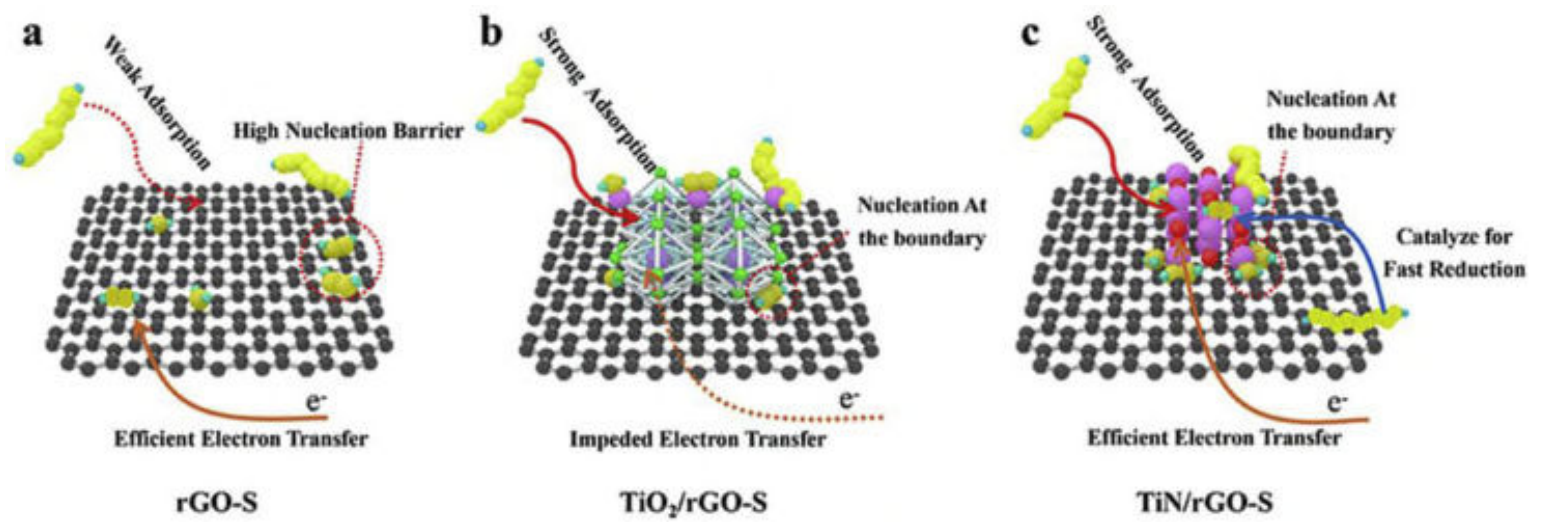

Fig. 7. Comparison of the adsorption mechanism of (a) rGO-S, (b) $\mathrm{TiO}_{2} / \mathrm{rGO}-\mathrm{S}$ and (c) TiN/rGO-S.

\section{Conclusions}

In summary, graphene-supported TiN nanoparticles hybrid was quickly synthesized by microwave reduction nitridation methods. The hybrid can serve as the sulfur host material for enhancing adsorption ability to polysulfide and reaction kinetics in $\mathrm{Li}-\mathrm{S}$ batteries. $\mathrm{We}$ demonstrated that the TiN/rGO composites possess both a high electrical conductivity for electron transfer and polar surface for strong $\mathrm{LiPSs} / \mathrm{Li}_{2} \mathrm{~S}$ binding. This is not the case for $\mathrm{TiO}_{2} / \mathrm{rGO}$ and $\mathrm{rGO}$. The developed TiN/rGO-S bifunctional electrode with $61.05 \%$ wt. sulfur content exhibits a high initial specific discharging capacity of $1197.6 \mathrm{mAh} \mathrm{g}^{-1}$ and retains a reversible capacity of $888.7 \mathrm{mAh} \mathrm{g}^{-1}$ after 150 cycles at $0.1 \mathrm{C}$. When the sulfur content reaches $79.62 \%$ wt., a discharging capacity of $700 \mathrm{mAh} \mathrm{g}^{-1}$ is achieved at $1 \mathrm{C}$, and capacity of 460 $\mathrm{mAh} \mathrm{g}^{-1}$ is retained after 500 cycles with a capacity loss of about $0.13 \%$ per cycle. Therefore, we believe that this strategy can create an effective avenue for manufacturing other graphene 
supported early-transition-metal carbonitrides not just for $\mathrm{Li}-\mathrm{S}$ battery, but also potential applications in catalysis, supercapacitor, adsorption and other energy storage devices.

Author contributions section

Author 1: Jianxin Tu: Conceived and designed the study, Performed the experiments, Collected the data, Performed the analysis, Wrote the paper.

Author 2: Hejun Li: Conceived and designed the study, Reviewed and edited the manuscript. Author 3: Tongbin Lan: Contributed data and analysis tools, Reviewed and edited the manuscript.

Author 4: Shao-Zhong Zeng: Contributed data and analysis tools, Reviewed and edited the manuscript.

Author 5: Jizhao Zou: Reviewed and edited the manuscript.

Author 6: Qi Zhang: Reviewed and edited the manuscript.

Author 7: Xierong Zeng: Conceived and designed the study. Reviewed and edited the manuscript.

Acknowledgements

The authors appreciate support by the Shenzhen Basic Research Program (No. JCYJ20170818100134570, JCYJ20160422091418366), China Postdoctoral Science Foundation (No. 2019M663054). Thanks for TEM measurement help of Instrumental Analysis Center of Shenzhen University (Xili Campus). 
Facile synthesis of TiN nanocrystals/graphene hybrid to chemically suppress the shuttle effect for lithium-sulfur batteries

\author{
Tu, Jianxin
}

Elsevier

Tu J, Li H, Lan T, et al., (2020) Facile synthesis of TiN nanocrystals/graphene hybrid to chemically suppress the shuttle effect for lithium-sulfur batteries. Journal of Alloys and Compounds, Volume 822, May 2020, Article number 153751

10.1016/j.jallcom.2020.153751

Downloaded from Cranfield Library Services E-Repository 